\title{
NOVOS EMPREENDIMENTOS: DIFICULDADES E BARREIRAS INSTITUCIONAIS PARA ABERTURA DE MICRO E PEQUENAS INDÚSTRIAS EM VITÓRIA DA CONQUISTA-BA
}

\section{New enterprises: difficulties and institutional barriers for the opening of micro and small industries in Vitória da Conquista-BA}

\section{Nuevos emprendimentos: dificultades y barreras institucionales para la apertura de micro y pequeñas industrias en Vitória da Conquista-BA}

\author{
Nilton Ribeiro Almeida ${ }^{1}$ \\ Allisianne Krystina S. de Figueiredo ${ }^{2}$ \\ Rita de Cássia O. Lima Alves ${ }^{3}$
}

\footnotetext{
${ }^{1}$ Graduado em Administração pela Universidade Estadual do Sudoeste da Bahia. Email: nilton.ribeiro@ hotmail.com

${ }^{2}$ Mestre em Economia Regional e Políticas Públicas. Técnica da Universidade Estadual do Sudoeste da Bahia - UESB.

Email: aksfigueiredo@uesb.edu.br

${ }^{3}$ Doutora em Planificação Territorial e Gestão Ambiental. Professora Adjunta da Universidade Estadual do Sudoeste da Bahia. Email: rcassialimaa@gmail.com
}

\begin{abstract}
Resumo
As micro e pequenas empresas correspondem à maioria dos estabelecimentos no Brasil, assim como em Vitória da Conquista, assumindo grande importância econômica e social. Esta pesquisa objetivou identificar as dificuldades dos empresários das micro e pequenas indústrias, quanto aos processos de abertura de empresas fundadas nos anos de 2015 e 2016. O estudo teve caráter exploratório e descritivo, utilizando-se o estudo de caso múltiplo. Observou-se alto grau de insatisfação em relação às etapas de abertura das empresas, sobretudo em relação ao excesso de burocracia, o que implicou em maior morosidade das ações. Evidenciou-se, portanto, a necessidade de melhorias, a exemplo da evolução de normatizações e estruturas burocráticas, no sentido de promover a celeridade dos processos de abertura de empresas.
\end{abstract}

Palavras-chave: Micro e pequenas empresas; Abertura de empresas; Melhorias.

\begin{abstract}
Micro and small enterprises correspond to most establishments in Brasil, as well as in Vitória da Conquista, assuming great economic and social importance. This study aimed to identify the difficulties faced by entrepreneurs in micro- and small-scale industries in the opening of companies founded in the years 2015 and 2016. The study was exploratory and descriptive, using the multiple case study. There was a high degree of dissatisfaction with the opening stages of the companies, especially in relation to the excess of bureaucracy, which implied a greater slowness of actions. The need for improvements, such as the evolution of regulations and bureaucratic structures, has been evidenced in order to promote the speed of business start-ups.
\end{abstract}

Keywords: Micro and small companies; Opening of companies; Improvements. 


\section{Resumen}

Las micro y pequeñas empresas corresponden a la mayoría de los establecimientos en Brasil, así como en Vitória da Conquista, asumiendo gran importancia económica y social. Esta investigación objetivó identificar las dificultades de los empresarios de las micro y pequeñas industrias, en cuanto a los procesos de apertura de empresas fundadas en los años de 2015 y 2016. El estudio tuvo carácter exploratorio y descriptivo, utilizando el estudio de caso múltiple. Se observó alto grado de insatisfacción en relación a las etapas de apertura de las empresas, sobre todo en relación al exceso de burocracia, lo que implicó en mayor morosidad de las acciones. Se evidenció, por lo tanto, la necesidad de mejoras, a ejemplo de la evolución de normativas y estructuras burocráticas, en el sentido de promover la celeridad de los procesos de apertura de empresas.

Palabras clave: Micro y pequeñas empresas; Apertura de empresas; Mejoras.

\section{Introdução}

As micro e pequenas empresas (MPE's) possuem grande relevância no desenvolvimento econômico e social do país. Até o ano de 2015, os pequenos negócios representavam, aproximadamente, 98,5\% do total de empresas privadas, absorvendo $54 \%$ do total de empregos em torno de 17.560 .777 pequenos negócios, dentre micro empreendedores individuais, micro empresas, empresas de pequeno porte, produtores rurais e artesãos (SEBRAE, 2017a). Neste contexto, ao iniciar a formalização de uma empresa, exige-se do empreendedor, uma série de iniciativas requerendo planejamento, no qual todas as etapas, desde a implantação até sua maturidade, devem ser bem definidas e estabelecidas antes de sua abertura. A fase de implantação da empresa, costuma, portanto, ser onerosa e árdua, sobretudo em função das dificuldades para o cumprimento da legalização frente aos órgãos responsáveis. Tais dificuldades prejudicam, tanto os empresários como a economia, no qual o tempo que é necessário para ter acesso ao alvará de funcionamento, impede a empresa de gerar renda, empregos. E, consequentemente, prejudica a arrecadação de impostos, os quais poderiam beneficiar, de forma mais ágil à população de um determinado ambiente.

De acordo com Alves (2014) nos padrões de regionalização identificados, Vitória da Conquista foi sempre reconhecida como cidade pólo, em função do comando que exerce na sua região de influência. Ou seja: no padrão de regionalização das Regiões Econômicas do Estado, Vitória da Conquista foi categorizada como cidade sede da Região Sudoeste. Ainda no atual padrão de regionalização dos Territórios de Identidade, Vitória da Conquista estabeleceu-se como cidade sede da microrregião de mesma denominação, ou seja: Microrregião de Vitória da Conquista do Território de 
Identidade do Centro Sul da Bahia. Por fim, os estudos do REGIC, da esfera federal, considera nacionalmente Vitória da Conquista como Capital regional B, tendo em vista o nível de centralidade identificado na sua região de influência.

Em relação à economia do munícípio, verifica-se o baixo crescimento relativo do seu Produto Interno Bruto (PIB), nos últimos anos, cujas característcas mais fortes estão centradas nas micro e pequenas empresas. Este contexto se reflete em um PIB de resultdos pouco significativos para o estado da Bahia. Como consequência, verifica-se um quadro de extrema pobreza nesta região, onde problemas econômicos e sociais ainda necessitam ser superados, desde a fase inicial, relacionada à abertura de empresas até estratégias mais amplas de ação que permitiriam um maior crescimento e desenvolvimento deste ambiente.

As MPEs representam 98,7\% do total das empresas da cidade, correspondendo a aproximadamente 32.412 empresas, segundo estimativas do Empresômetro Inteligência de Mercado (IBPT, 2017). Ainda segundo essa fonte, essa proporção também é quase absoluta se compararmos com o setor industrial, no qual, a cidade possui 3.371 MPEs e MEIs, dentro de um universo de 3397, indústrias. Diante do exposto, o setor industrial representa aproximadamente, apenas $10 \%$ do total de indústrias da cidade.

Ante o exposto, as reflexões sobre os aspectos relacionados às dificuldades para abertura de empresas, portanto, têm se materializado, ao longo dos anos, por meio de variadas ações e consequentes discussões sobre o tema. Este, por sua vez, nos remete a tais questionamentos: Quais e como identificar tais dificuldades? Qual a posição que Vitória da Conquista assume frente a tal condição? Estariam as empresas de Vitória da Conquista, contempladas com o tempo minimamente aceitável ao atual processo de abertura de empresas, de forma que esta etapa não caracterize um entrave no processo de empreendedorismo e consequente estímulo à agilidade das atividades produtivas deste ambiente?

Nesse contexto, pretende-se, para tanto, responder aos questionamentos acima, buscando alcançar as respostas a partir do seguinte problema central: Quais as principais dificuldades no processo de abertura de empresas apontadas por empresários que constituíram Micro e Pequenas Empresas (MPEs) Industriais no período de 2015 e 2016 na cidade de Vitória da Conquista?

Objetivando responder à questão problema do presente estudo, foi realizada uma pesquisa de caráter teórico e empírica. Segundo Demo (2000) a pesquisa é de caráter 
teórico, uma vez que buscará reconstruir teoria, conceitos, ideias, tendo em vista, aprimorar fundamentos teóricos. A pesquisa empírica, segundo Demo (2000), é dedicada ao tratamento da face empírica e factual da realidade, produz e analisam dados procedendo sempre pela via do controle empírico e fatual. Ou seja, foram coletados dados em campo, arrecadando informações relevantes para responder a problemática da pesquisa. A presente pesquisa caracteriza-se também como descritiva, porque visa descrever as principais dificuldades enfrentadas por empreendedores do segmento industrial ao abrir uma empresa na cidade de Vitória da Conquista. A pesquisa é também exploratória, pelo ineditismo do tema, com poucos estudos acadêmicos de que se tem conhecimento, na cidade de Vitória da Conquista.

Assim, a presente investigação adotou, inicialmente, a pesquisa bibliográfica acerca do tema, assim como a legislação que o rege para embasamento do estudo; de forma a se conhecer mais profundamente o problema estudado. Através do levantamento bibliográfico, encontrou-se ainda uma técnica de análise dos dados coletados nos questionários, que pudesse auxiliar na resposta ao problema da pesquisa.

Como unidade de análise adotou-se as micro e pequenas empresas industriais da cidade de Vitória da Conquista que iniciaram suas atividades nos anos de 2015 e 2016. Nesse período foram abertas 57 empresas com essas características na cidade. Destas, 11 estão localizadas no centro da cidade e compõem a população da pesquisa. Tais dados foram coletados no site Empresômetro Listas (IBPT, 2017).

Para essa pesquisa foi adotado o questionário estruturado, ou seja, foram usadas questões fechadas e de múltipla escolha, a fim de possibilitar a análise quantitativa dos dados obtidos. Além disso, foram utilizadas também questões abertas correlacionadas às fechadas, para compreender melhor como os entrevistados pensam a respeito das opções marcadas. Com a finalidade de validar o questionário, foi realizado um pré-teste com quatro empresários da cidade de Vitória da Conquista que abriram suas empresas recentemente. A cada questionário aplicado eram observadas dúvidas e possibilidades de melhoria em variadas questões.

Este estudo objetiva, assim, analisar o grau de dificuldade que micro e pequenas empresas industriais de Vitória da Conquista possuem quanto à abertura dos seus empreendimentos, durante os períodos de 2015 e 2016. Para tanto, apresentar-se-á os procedimentos metodológicos. Em seguida, adentrar-se-á às principais concepções e 
demais aspectos sobre micro e pequenas empresas, para, na sequência, apresentar e analisar os principais resultados da pesquisa.

\section{Micro e Pequenas Empresas: principais concepções e categorizações}

Os conceitos de micro e pequena empresa foram uniformizados pela Lei complementar no 123/2006, denominada de Lei Geral da Micro e Pequena Empresa, ao adotar como base referencial a receita bruta anual, decorrente das atividades da empresa. A Lei Complementar $n^{\circ}$ 155/2016 atualiza a Lei Geral da Micro e Pequena Empresa, acrescentando outros parâmetros para mensuração do porte das MPE's, conforme disposto no Quadro 1:

Quadro 01. Classificação do porte das Micro e Pequenas empresas

\begin{tabular}{|l|c|c|c|}
\hline \multirow{2}{*}{ Tipo de MPE } & $\begin{array}{c}\text { Lei Complementar } \\
\mathbf{n}^{\mathbf{0}} \mathbf{1 2 3 / 2 0 0 6}\end{array}$ & $\begin{array}{c}\text { Lei Complementar } \\
\mathbf{n}^{\mathbf{0}} \mathbf{1 5 5 / 2 0 1 6}\end{array}$ & \multicolumn{2}{|c|}{ BNDES } \\
\cline { 2 - 4 } & & \multicolumn{3}{|c|}{ Faturamento } \\
\hline Microempresa & Até R\$ 360 mil & Até R\$ 2.4 milhões \\
\hline $\begin{array}{l}\text { Empresa de } \\
\text { Pequeno Porte }\end{array}$ & & $\begin{array}{c}>\mathrm{R} \$ 360 \text { mil } \\
<\mathrm{R} \$ 4.8 \text { milhões }\end{array}$ & $\begin{array}{c}>\mathrm{R} \$ 2.4 \text { milhões } \\
<\mathrm{R} \$ 16 \text { milhões }\end{array}$ \\
\hline
\end{tabular}

Fonte: Brasil, (2006; 2016); BNDES (2015). Dados organizados pelos autores.

Os valores fixados pela Lei Complementar $n^{\circ}$ 155/2016 correspondem a receitas adquiridas no mercado nacional, podendo ela obter adicional sobre a receita anual de exportação de, no máximo, à $\mathrm{R} \$ 4.800 .000,00$. A classificação de porte de empresa adotada pelo Banco Nacional de Desenvolvimento Econômico e Social é utilizada para enquadramento das condições de suas linhas e programas de financiamento. Isso acontece porque as condições financeiras podem variar em função do porte da empresa que solicita o financiamento. (BNDES 2015).

O Serviço Brasileiro de Apoio às Micro e Pequenas Empresas (SEBRAE, 2017b) utiliza outro tipo de classificação para as MPEs. Em sua definição, a diferença ocorre pelo número de funcionários, como pode ser observado no Quadro 2.

Quadro 02. Classificação micro e pequenas empresas SEBRAE

\begin{tabular}{|c|c|}
\hline CLASSIFICAÇÃO MICRO E PEQUENAS EMPRESAS SEBRAE \\
\hline \multicolumn{2}{|c|}{ Comércio e serviços } \\
\hline Classificação & Faturamento anual \\
\hline Micro empresa & Até 9 funcionários \\
\hline
\end{tabular}




\begin{tabular}{|c|c|}
\hline Pequena empresa & Entre 10 e 49 funcionários \\
\hline & Indústria \\
\hline Classificação & Faturamento anual \\
\hline Micro empresa & Até 19 funcionários \\
\hline Pequena empresa & Entre 20 e 99 funcionários \\
\hline
\end{tabular}

Fonte: SEBRAE (2017b). Dados organizados pelos autores

Outra classificação de porte para os pequenos negócios é o MEI. A Lei Geral da Micro e Pequena Empresa de 2006 foi responsável pela sua criação, no qual, classifica o empresário como MEI aquela pessoa que trabalha por conta própria e se legaliza como pequeno empresário optante pelo Simples Nacional, com receita bruta anual de até $\mathrm{R} \$$ 81.000,00, atualizada pela Lei Complementar $n^{\circ}$ 155/2016. O microempreendedor pode possuir um único empregado que deve receber salário mínimo ou o mínimo permitido pela categoria e não pode ser sócio ou titular de outra empresa.

De acordo, dados fornecidos pelo SEBRAE (2017c), as MPEs adquiriram, por volta dos últimos trinta anos, uma relevância ascendente no país, pois é inegável o importante papel socioeconômico desempenhado pelas mesmas. As seguintes informações confirmam tal afirmativa em distintas dimensões da realidade nacional:

- As MPEs atingiram em 2011, 27,0\% do valor do PIB no país;

- Esse percentual vem aumentando na série histórica, iniciada em 1985, quando esse indicador representava de $21,0 \%$ do PIB, e em 2001, 23,2\%;

- Serviços e comércio representaram, em 2011, $19 \%$ do valor, enquanto a indústria totalizava $7,8 \%$;

- Em relação ao número de empresas as MPE representaram, em 2011, nas atividades de serviços e de comércio, respectivamente, $98 \%$ e $99 \%$ do total de empresas formalizadas;

- Em relação ao emprego, as MPE representavam 44\% dos empregos formais em serviços, e aproximadamente $70 \%$ dos empregos gerados no comércio;

- Cerca de 50\% das remunerações do setor formal de comércio foram pagas, em 2011, por MPE. (SEBRAE, 2017c).

Considerando o exposto é incontestável, portanto, o grande papel que as MPEs desempenham no cenário econômico e social do país. A porcentagem de participação no

Produto Interno Bruto (PIB) e de empregos com carteira assinada aponta a grande importância que as MPEs proporcionam ao país.

\section{Processo de abertura de empresas}


Legalmente, os procedimentos para abertura de uma empresa podem ser realizados pessoalmente pelo empresário. O processo é realizado, no entanto, de forma mais rápida ao se contratar um profissional especializado, o contador. Tal profissional possui o conhecimento para realizar todos os procedimentos, otimizando o tempo. Os contadores, portanto, são considerados os profissionais mais capacitados para realizarem a abertura de empresas com agilidade e confiabilidade, que de acordo com o SEBRAE, deve-se iniciar com os seguintes procedimentos:

1. Consulta de viabilidade do nome empresarial: verificar junto à prefeitura onde a empresa será instalada sobre os critérios para concessão do Alvará de Funcionamento para o exercício da atividade no local escolhido. Nesta etapa é necessário apresentar vários documentos e formulários, e estes podem variar de um estado para outro. Os documentos mais comuns são o Contrato Social, além da documentação pessoal dos sócios;

2. Registrar a empresa na Junta Comercial ou Cartório de Registro da Pessoa Jurídica. Nesta etapa é gerado Número de Identificação do Registro de Empresa (NIRE). A partir desse número é gerado o Cadastro Nacional da Pessoa Jurídica (CNPJ);

3. Registro do CNPJ que permite o cadastro de uma atividade principal e até 14 atividades secundárias. Para as empresas que trabalham com a produção de bens e/ou com venda de mercadorias é necessário o registro na Secretaria Estadual da Fazenda, a Inscrição Estadual.

4. Para as empresas que trabalham com a produção de bens e/ou com venda de mercadorias é necessário o registro na Secretaria Estadual da Fazenda, a chamada Inscrição Estadual. Para as empresas que trabalham com prestação de serviços é necessário o registro na Prefeitura Municipal.

5. Alvará do Corpo de Bombeiros: as edificações e áreas de risco de incêndio deverão possuir Alvará de Prevenção e Proteção Contra Incêndio - APPCI.

6. Alvará de funcionamento e localização, uma licença prévia expedida pelo município para funcionar.

7. Após o alvará de funcionamento, a empresa pode operar e deve efetuar o seu cadastro na Previdência Social, independente da empresa possuir funcionários.

8. Por fim, prepara-se o aparato fiscal, autorização para emissão de notas físcais e a autenticação de livros fiscais. (SEBRAE, 2017d). 
Medidas estão sendo tomadas para facilitar os processos de abertura de MPEs "O SEBRAE, juntamente com os órgãos de registro e licenciamento, estão buscando a implantação da REDESIM para simplificar e desburocratizar os procedimentos de abertura." (SEBRAE, 2017d). Com o REDESIM, o empreendedor ao formalizar seu negócio, necessitará dar somente uma entrada de dados cadastrais e documentos, o que resultará em uma redução do tempo gasto para legalização da empresa. Segundo dados da Prefeitura de Vitória da Conquista (PMVC, 2017), a cidade começou a fazer parte do Registro Integrado (REGIN) em abril de 2014 e então o REDESIM começou a ter vigência.

Apresenta-se na figura 1 o fluxograma do processo de abertura de empresas, resumindo as etapas supracitadas.

Figura 01- Fluxograma do processo de abertura de empresas

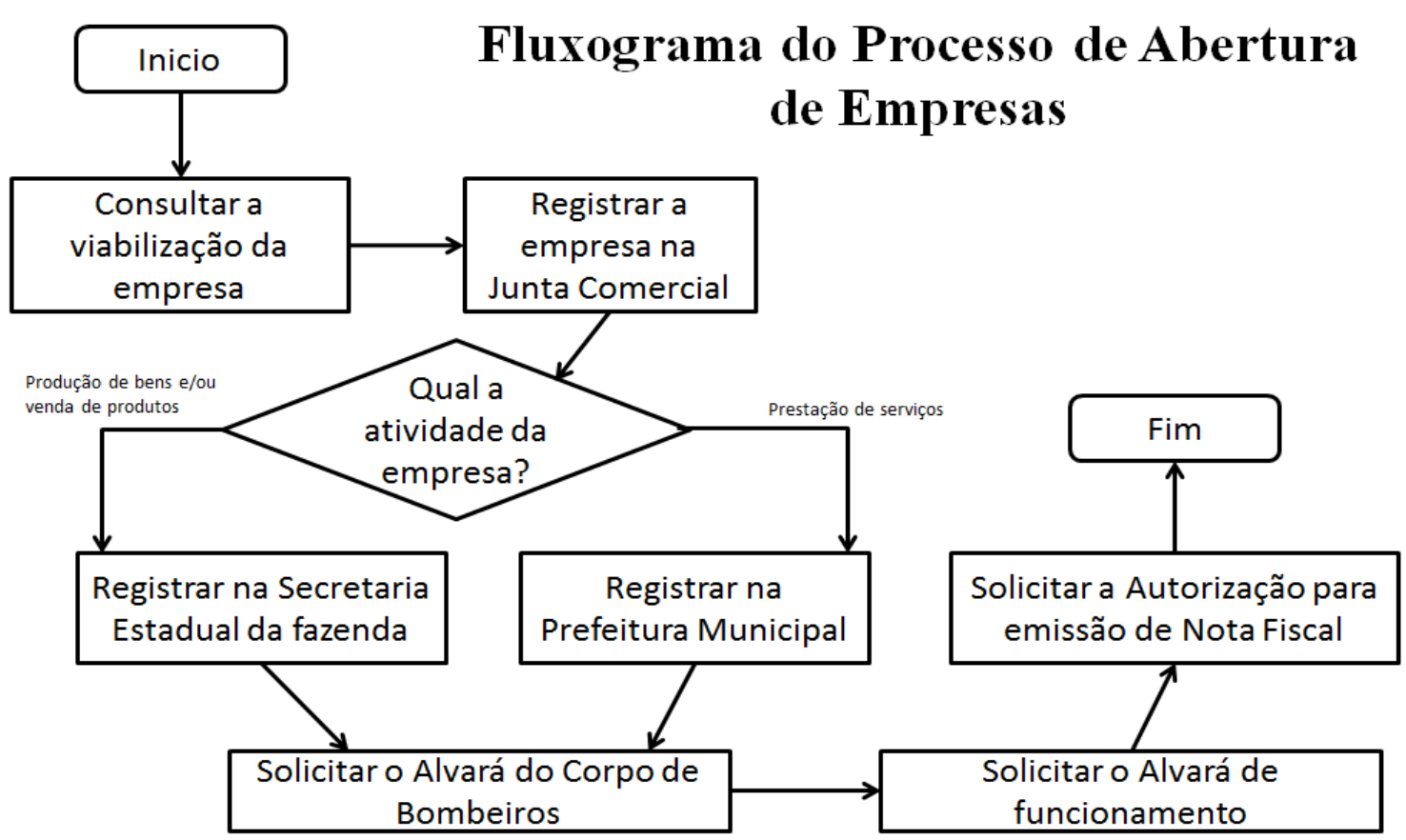

Fonte: Dados organizados pelos autores.

Ante o exposto, observa-se o grau de complexidade das etapas que envolvem o processo de abertura das empresas, implicando, certamente, em dificuldades que empresários enfrentam constantemente logo na formação da empresa. Dentre essas dificuldades, Roveda (2016) cita as três mais comuns: o excesso de burocracia, a falta de orientação qualificada e suportar as despesas durante o processo de registro. 
Roveda (2016) explica, quais são os principais empecilhos impostos pelo excesso de burocracia:

- $\quad$ O número de licenças, inscrições e alvarás necessários para abrir uma empresa pode variar muito de acordo com o seu tamanho, forma de constituição e ramo de atividade. O registro de uma empresa se inicia na Junta Comercial ou no Cartório de Pessoas Jurídicas de seu Estado, onde você terá que entregar cópias de diversos documentos.

- $\quad$ O segundo passo é a obtenção do CNPJ com o cadastro na Receita Federal do Brasil, ocasião em que você precisará entregar novamente cópias de vários documentos, inclusive de alguns já entregues na Junta Comercial.

- $\quad$ Posteriormente, terá que obter o alvará de localização e funcionamento, realizar sua inscrição na secretaria de fazenda do Estado que está a sua empresa, se cadastrar no INSS. Também precisará de diversas licenças e inscrições nos órgãos de regulação estaduais e municipais, dependendo das características de sua empresa. E em todas essas etapas você precisará apresentar praticamente os mesmos documentos. (ROVEDA 2016)

Diante desse excesso de burocracia e ineficiência por parte dos processos de formalização de empresas citado por Roveda (2016), é possível observar que um dos principais problemas identificados é a solicitação da mesma documentação várias vezes. Esse problema poderia facilmente ser resolvido ao se unificar todos os cadastros em um único órgão. Isso evitaria a apresentação do mesmo documento diversas vezes, reduzindo o trabalho e o tempo gasto com cadastros.

O segundo aspecto apontado por Roveda (2016) é a falta de orientação qualificada a qual pode estar presente tanto na pessoa que está abrindo o negócio como nos funcionários do órgão público. Um acontecimento comum é ter que voltar várias vezes ao mesmo órgão por falta de algum documento, não verificado pelo funcionário competente, de todos os documentos ou por falta de conhecimento dos documentos necessários por parte do empresário.

Por último, Roveda (2016) ainda aponta que suportar as despesas durante o processo de registro é outro grande desafio enfrentado pelos empreendedores. O processo de abertura não é gratuito, pois possuem despesas diretas que são pagas à Junta Comercial e outras taxas próprias de registro, além de incidir também despesas indiretas como aluguel, reforma de ponto, honorários do contador. Todos esses gastos pesam no 
bolso do empresário, que, ao se deparar com um processo lento, tem ainda que estar preparado para pagar essas despesas.

\section{Indústria}

A indústria, juntamente com a agricultura, pecuária, extrativismo (setor primário), e os serviços (setor terciário), integram a economia nacional. A Indústria refere-se ao setor secundário, responsável pelo processamento da produção do setor primário, que resulta na geração de bens de consumo, construção civil e geração de energia.

Historicamente, no Brasil a industrialização chegou em meados do século XIX, trazendo avanços que ora o país não apresentava. Retomando FURTADO (1976), abaixo é descrito um pouco da chegada industrial ao Brasil.

O processo de industrialização começou no Brasil concomitantemente em quase todas as regiões. Foi no Nordeste que se instalaram, após a reforma tarifária de 1844, as primeiras manufaturas têxteis modernas e, ainda em 1910, o número de operários têxteis dessa região se assemelhava ao de São Paulo. Entretanto, superada a primeira etapa de ensaios, o processo de industrialização tendeu naturalmente a concentrar-se nessa região. A etapa decisiva de concentração ocorreu, aparentemente, durante a Primeira Guerra Mundial, época em que teve lugar à primeira fase de aceleração do desenvolvimento industrial [...]. (FURTADO, 1976, P. 238).

O setor industrial é reconhecido por diversas teorias econômicas como fator condicionante do crescimento econômico, por isso a sua relevância para o desenvolvimento de um país ou região. Adam Smith considerava que o desenvolvimento seria alcançado pela elevação da renda média e redução do desemprego, e tinha na indústria a base para o desenvolvimento das forças produtivas necessárias ao crescimento (SOUZA, 2005). Perroux (1967) em sua Teoria de Polarização, ou dos Polos de Crescimento, preconizava o setor industrial como motor do crescimento econômico. Dessa forma, a instalação de uma indústria motriz na região promoveria a difusão do progresso técnico pela geração de novas tecnologias e produtos com maior valor agregado, com efeitos de encadeamento sobre outras atividades e indústrias, além de absorver mão de obra especializada e com melhores salários (FIGUEIREDO, 2016). 


\section{Vitória da Conquista enquanto espaço de desenvolvimento e crescimento} econômico

Vitória da Conquista, segundo dados do IBGE (2017), em 2016 registrou uma população de 346.069 habitantes, categorizando-a como $3^{\text {a }}$ maior cidade do estado da Bahia. Um aumento de $13 \%$ se comparado com 2010 como podemos observar nas informações sobre a cidade apresentadas por Alves (2014).

Com uma população que, em 2010, alcança 306.374 habitantes, o que equivale a aproximadamente $2,19 \%$ da população baiana, Vitória da Conquista tem reforçado nos últimos anos o seu posicionamento de $3^{\mathrm{a}}$ maior cidade do estado em número de habitantes. Atraídos pelas possibilidades de acesso ao trabalho, educação e saúde, é grande o contingente de pessoas que faz deste território o destino certo para esse pólo regional baiano. Os aspectos ora apresentados dinamizaram e aumentaram a quantidade de moradores de Vitória da Conquista. (ALVES, 2014, p. 297).

Tais possibilidades de acesso ao trabalho, educação e saúde são decorrentes da localização estratégica que Vitória da Conquista se encontra. Como apontado por Alves (2014) as rodovias que passam pela cidade se caracterizam como importantes vetores de crescimento urbano. Tais rodovias proporcionam uma importante interligação regional.

As MPEs, juntamente com as MEI representam 98,7\% do total das empresas da cidade, correspondendo a aproximadamente 32.412 empresas, segundo estimativas do Empresômetro Inteligência de Mercado (IBPT, 2017). Nos anos de 2015 e 2016 foram abertos 57 micro e pequenas empresas industriais na cidade, em diferentes ramos de atividade (IBPT, 2017).

A quantidade de micro e pequenas empresas industriais e seus respectivos bairros podem ser observadas no mapa da figura 2. A maior parte delas está localizada no centro, no qual, nesse bairro totaliza 11 empresas, sendo 9 (nove) microempresas e 2 (duas) de pequeno porte. As demais empresas estão distribuídas entre os demais bairros da cidade. Os micro e pequenos estabelecimentos industriais de maior representatividade encontram-se nas áreas de fabricação de produtos de panificação, confecção de roupas e manutenção e reparação de equipamentos, geradores e máquinas (IBPT, 2017). 
Figura 02- Mapa dos Bairros de Vitória da Conquista

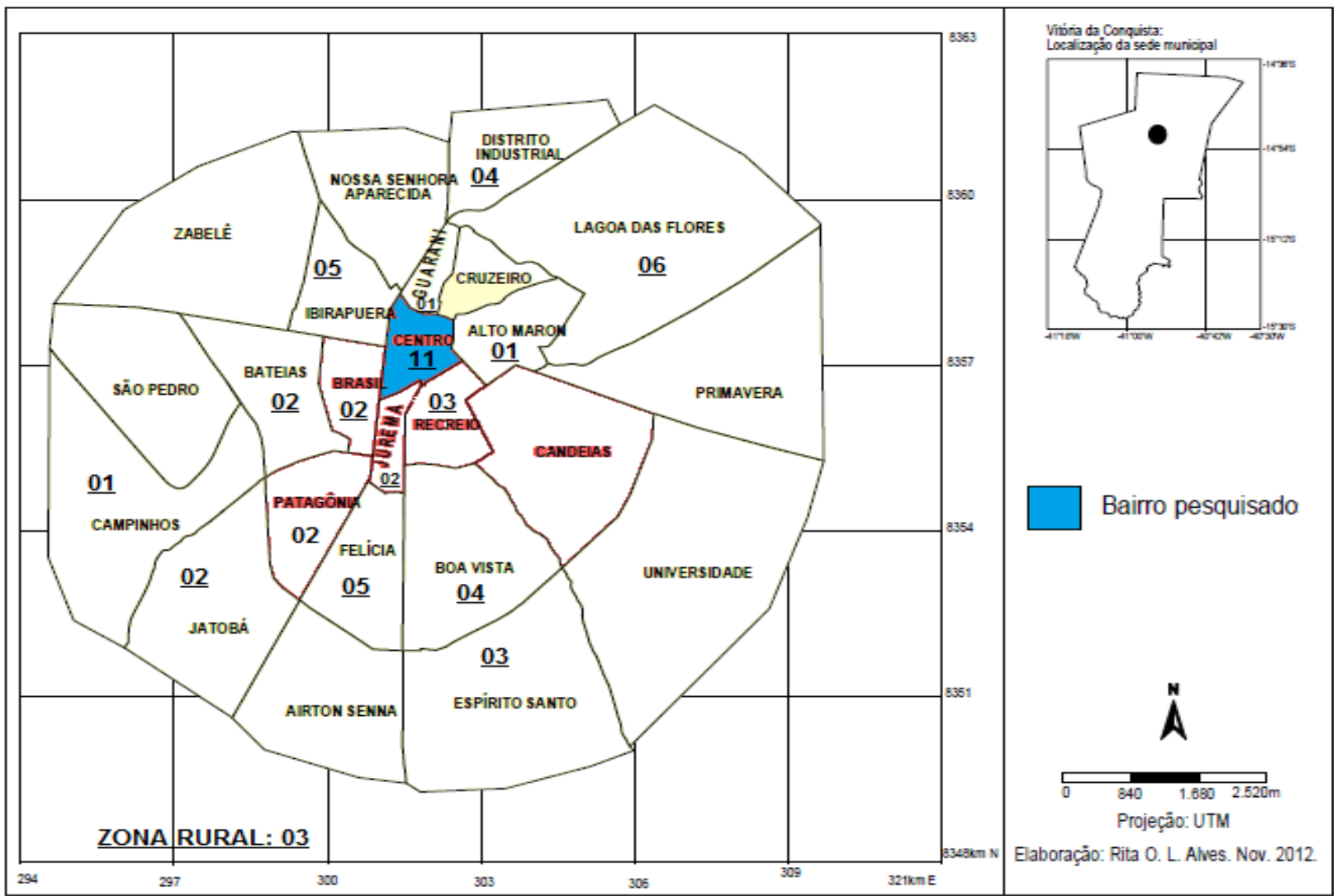

Fonte: ALVES, 2014.

\section{A abertura de empresas: aspectos funcionais}

No Brasil, a média de tempo para abertura de empresas é de 79,5 dias segundo dados do World Bank (2017). A maior parte das empresas pesquisadas indicou que demoraram acima de 80 dias para abrir suas empresas (Figura 3). Ao se adicionar ao somatório, as empresas que abriram entre 61 e 80 dias, essa porcentagem passa da metade.

Figura 03- Tempo de abertura da empresa

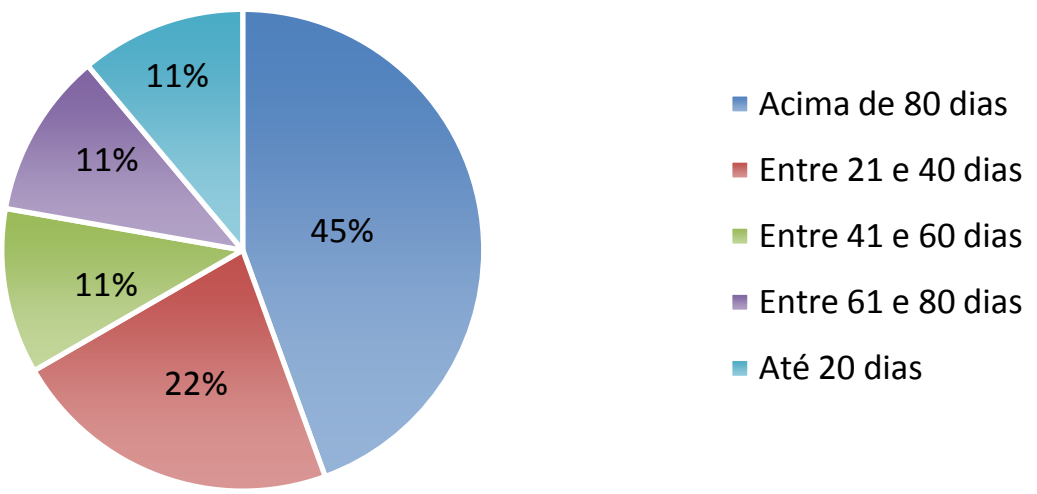

Fonte: Dados pesquisados e organizados pelos autores, 2017. 
Diante disso, é possível afirmar que o tempo para abertura das empresas pesquisadas está muito elevado, se comparado à média mundial. Enquanto a maioria das empresas pesquisadas necessitou de mais de 80 dias para iniciarem, legalmente, suas atividades; em países como Nova Zelândia, Canadá e Austrália a média de tempo necessária é entre 0,5 e 2 dias.

Figura 04 - Gráfico dos setores que exigem mais tempo que o necessário para dar continuidade no processo de abertura da empresa
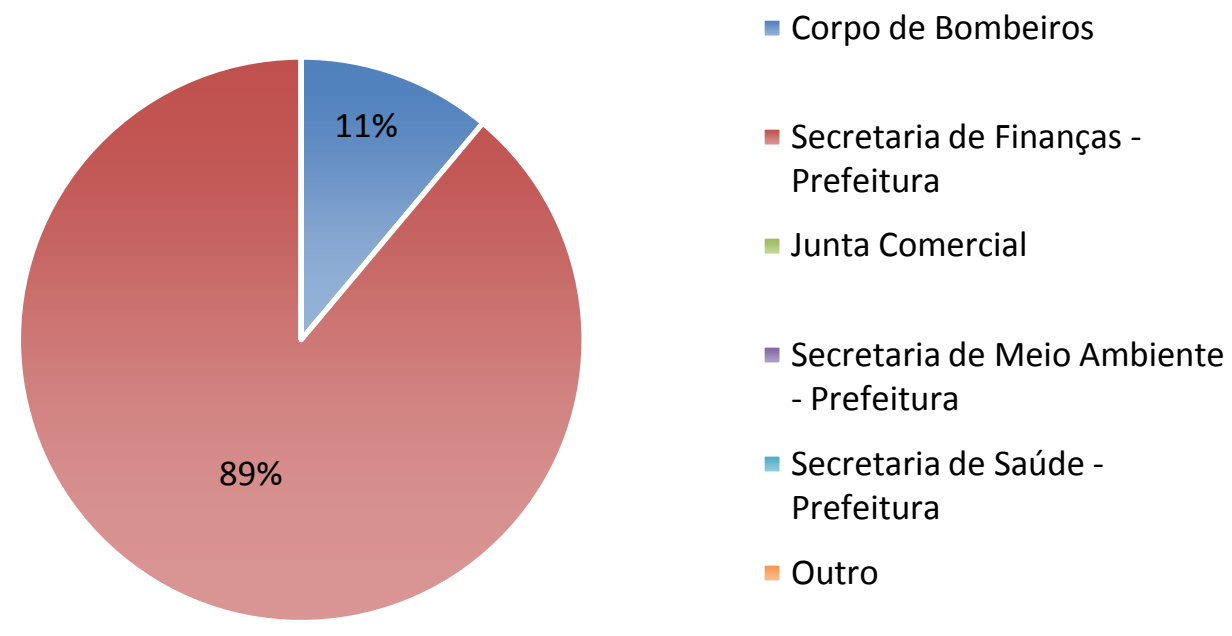

Fonte: Dados pesquisados e organizados pelos autores, 2017.

O alvará de licença e funcionamento possibilita o exercício das atividades de uma empresa. É no órgão responsável pela liberação de tal alvará que os empresários se deparam com uma maior morosidade. Com uma porcentagem de $88,9 \%$, conforme a Figura 4, os empresários pesquisados apontaram que a Secretaria de Finanças do Município como o órgão que mais demora em liberar o alvará. Evidencia-se por meio do estudo realizado, portanto, que a prefeitura, junto aos órgãos de competência, necessita gerar maior agilidade na liberação dos documentos que favorecem a abertura das empresas.

Em relação ao grau de eficiência dos servidores que trabalham nos órgãos ligados ao processo de abertura da empresa, a figura 5 demonstra que 55,6\% dos entrevistados apontam como pouco eficientes e 22,2\% como ineficiente. Ou seja, de forma negativa $77,8 \%$ aponta que o desempenho dos servidores não é eficiente. A insatisfação com o servidor público é um tema muito comentado. Muitas pessoas atribuem tal condição a uma cultura relacionada aos benefícios e estabilidade que os 
servidores possuem. Entretanto, muitas vezes eles também têm dificuldades com a burocracia que os impedem de exercer suas atividades com mais eficiência.

Figura 05. Gráfico do grau de eficiência do desempenho dos servidores que trabalham nos setores responsáveis pela abertura da empresa

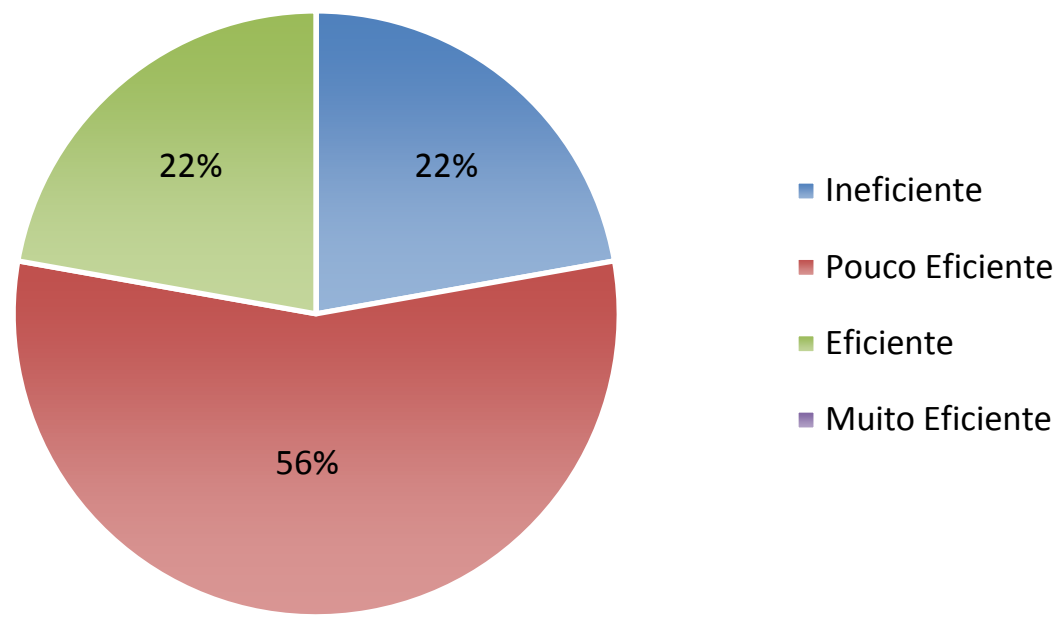

Fonte: Dados pesquisados e organizados pelos autores, 2017.

Somando aspectos que não indicam uma responsabilidade direta do servidor, conforme disposto na Figura 6, 41\% apontam que o baixo desempenho dos mesmos se deve à rigidez da burocracia e $18 \%$ que eles não possuem suporte tecnológico apropriado. Ou seja, 59\%, indicam que o problema não está com o servidor, mas sim com a burocracia e a falta de métodos tecnológicos para auxiliar nas atividades.

Figura 06. Atribuições que comprometem negativamente o desempenho dos servidores que trabalham nos setores responsáveis pela abertura da empresa.

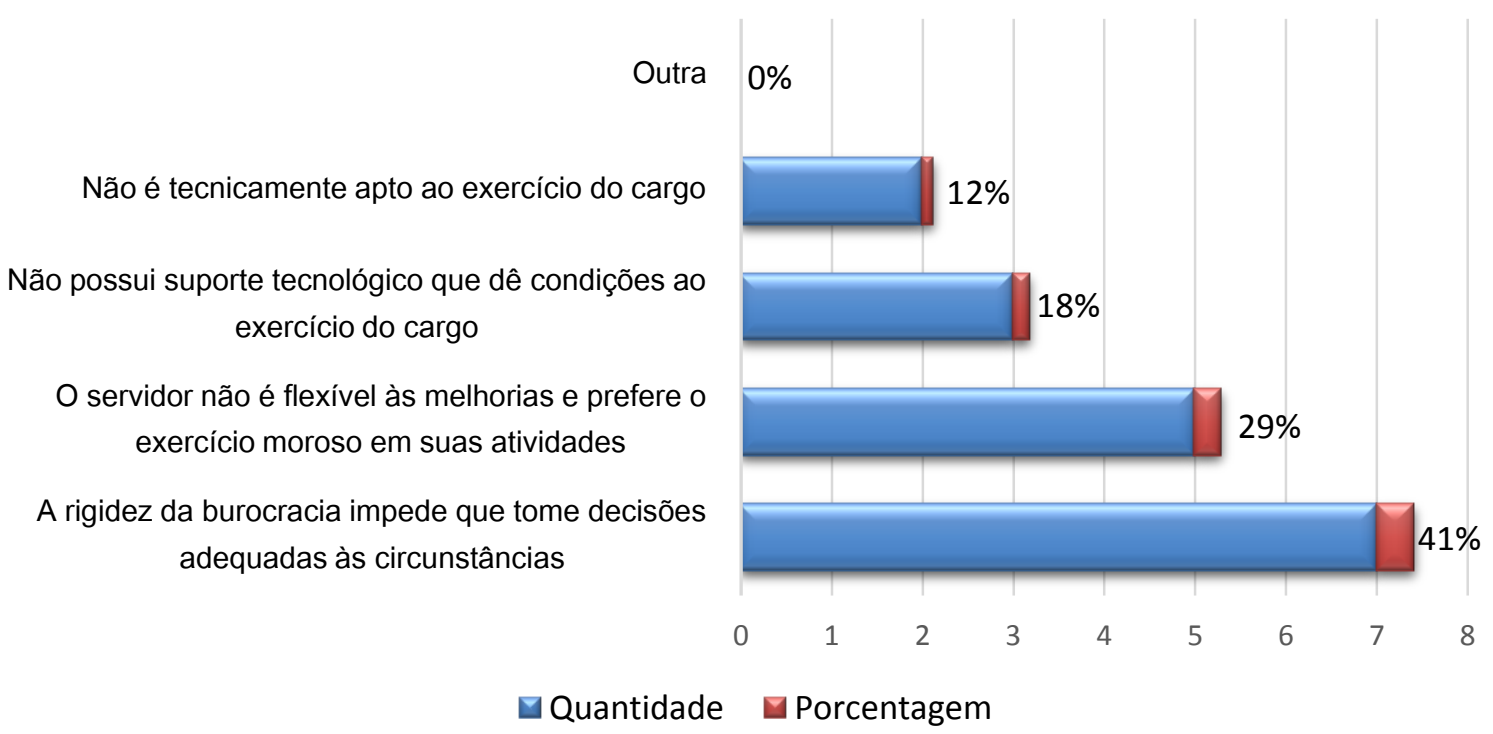

Fonte: Dados pesquisados e organizados pelos autores, 2017. 
Por outro lado, ao observar aspectos que responsabilizam diretamente o servidor, $29 \%$ aponta que eles não são flexíveis a mudanças e preferem o exercício moroso em suas atividades. Além disso, $12 \%$ apontam os servidores como tecnicamente incapazes. Essas atribuições que somam $41 \%$ das respostas, não é uma porcentagem baixa e potenciais melhorias devem ser analisadas e implementadas.

A maioria dos empresários entrevistados percebe a Junta Comercial como pouco eficiente. Entretanto, algumas também as classificaram como muito eficiente e eficiente, conforme informações da tabela 1. Isso equilibrou sua média que ficou em 2,78, próximo da nota três que é eficiente. Um motivo crucial para a eficiência da junta comercial é o REDESIM, que foi implantado na cidade em 2014. O REDESIM é um sistema unificado que facilita e recolhe toda a documentação para geração do CNPJ uma única vez, evitando a repetição de documentos para mais de um órgão e consequentemente o tempo de espera. Entretanto, por ainda gerar um pouco de insatisfação quanto à eficiência, deve ser estudado mais profundamente as questões que o fazem ser ineficiente, e se o REDESIM está realmente tendo os resultados propostos.

Tabela 01- Grau de Eficiência da Junta Comercial

\begin{tabular}{l|l|l|l|l}
\hline \multicolumn{5}{c}{ JUNTA COMERCIAL } \\
\hline Alternativa & Frequência (f) & Porcentagem & Peso (p) & F.P \\
\hline Ineficiente & 0 & $\mathbf{0 , 0 \%}$ & 1 & 0 \\
\hline Pouco Eficiente & 4 & $\mathbf{4 4 , 4 \%}$ & 2 & 8 \\
\hline Eficiente & 3 & $\mathbf{3 3 , 3 \%}$ & 3 & 9 \\
\hline Muito Eficiente & 2 & $\mathbf{2 2 , 2 \%}$ & 4 & 8 \\
\hline Total & 9 & & & 25 \\
\hline NOTA MÉDIA & \multicolumn{2}{|c}{2,78} \\
\hline
\end{tabular}

Fonte: Dados pesquisados e organizados pelos autores, 2017.

Dentre todos os órgãos pesquisados, o corpo de bombeiros foi o que obteve uma melhor avaliação. Segundo a tabela 2, sua nota de 2,89 está muito próxima de 3 , que é o grau que configura eficiência. Entretanto, ainda foi apontado com um pouco de ineficiência. Esse órgão possui diferentes exigências quanto ao tamanho da área construída, sendo que, para algumas empresas, as exigências são poucas e para outras são muitas, o que gera, muitas vezes, descontentamentos variados. 
Tabela 02- Grau de Eficiência do Corpo de Bombeiros

\section{CORPO DE BOMBEIROS}

\begin{tabular}{l|l|l|l|l}
\hline Alternativa & Frequência (f) & Porcentagem & Peso (p) & F.P \\
\hline Ineficiente & 0 & $\mathbf{0 , 0 \%}$ & 1 & 0 \\
\hline Pouco Eficiente & 2 & $\mathbf{2 2 , 2 \%}$ & 2 & 4 \\
\hline Eficiente & 6 & $\mathbf{6 6 , 7 \%}$ & 3 & 18 \\
\hline Muito Eficiente & 1 & $\mathbf{1 1 , 1 \%}$ & 4 & 4 \\
\hline Total & 9 & & & 26 \\
\hline NOTA MÉDIA & \multicolumn{2}{|c}{2,89} & \multicolumn{2}{l}{} \\
\hline
\end{tabular}

Fonte: Dados pesquisados e organizados pelo autor, 2017.

Quanto ao grau de eficiência podemos apontar a Secretaria de Finanças como o órgão menos eficiente segundo a pesquisa com os entrevistados (Tabela 3). Ela obteve uma nota média de 1,78 , na escala de 1 a 4 - menor e maior eficiência. Ante tal avaliação, a Secretaria de Finanças estaria classificada entre ineficiente e pouco eficiente. Os principais motivos apontados foram a organização, comunicação entre os setores e a demora na visita do fiscal ao local a ser avaliado.

Tabela 3- Grau de Eficiência da Secretária de Finanças.

\begin{tabular}{l|l|l|l|l}
\hline \multicolumn{5}{c}{ SECRETARIA DE FINANÇAS - PREFEITURA } \\
\hline Alternativa & Frequência (f) & Porcentagem & Peso (p) & F.P \\
\hline Ineficiente & 3 & $\mathbf{3 3 , 3 \%}$ & 1 & 3 \\
\hline Pouco Eficiente & 5 & $\mathbf{5 5 , 6 \%}$ & 2 & 10 \\
\hline Eficiente & 1 & $\mathbf{1 1 , 1 \%}$ & 3 & 3 \\
\hline Muito Eficiente & 0 & $\mathbf{0 , 0} \%$ & 4 & 0 \\
\hline Total & 9 & & & 16 \\
\hline NOTA MÉDIA & \multicolumn{4}{|c}{1,78} \\
\hline Fonte: Dados pesquisados e organizados pelos autores, 2017.
\end{tabular}

Entre as empresas pesquisadas, apenas uma empresa teve a necessidade da licença ambiental (tabela 4). O empresário atribuiu a nota 2, correspondente a pouco eficiente. Segundo correlação com o quadro 5, esse órgão acrescentou no tempo de abertura da empresa entre 15 a 25 dias. Tal prazo não é tão curto. Entretanto, depende, tanto da visita do fiscal, quanto do empenho do empresário, em se enquadrar logo as exigências necessárias. 
Tabela 04- Grau de eficiência da Secretária do Meio Ambiente

\begin{tabular}{c|c|c|c|c}
\hline \multicolumn{5}{c}{ SECRETARIA DO MEIO AMBIENTE - PREFEITURA } \\
\hline Alternativa & Frequência (f) & Porcentagem & Peso (p) & F.P \\
\hline Ineficiente & 0 & $\mathbf{0 , 0} \%$ & 1 & 0 \\
\hline Pouco Eficiente & 1 & $\mathbf{1 0 0 , 0 \%}$ & 2 & 2 \\
\hline Eficiente & 0 & $\mathbf{0 , 0} \%$ & 3 & 0 \\
\hline Muito Eficiente & 0 & $\mathbf{0 , 0} \%$ & 4 & 0 \\
\hline Total & 1 & & & 2 \\
\hline NOTA MÉDIA & \multicolumn{5}{|l}{} \\
\hline
\end{tabular}

Fonte: Dados pesquisados e organizados pelos autores, 2017.

Os dados aqui dispostos demonstram as barreiras existentes à implementação de novos empreendimentos, em razão principalmente da morosidade do aparato institucional existente. É fundamental que se reflita, discuta e implemente normatizações, leis e estruturas burocráticas que promovam a celeridade do processos de abertura de empresas, visto que a demora pode constituir-se como um fator desestimulante ao empreendedorismo.

\section{Considerações Finais}

Com base nos resultados obtidos, foi possível perceber que os setores pesquisados e envolvidos no processo de abertura de empresas, encontram-se abaixo do nível de eficiência, segundo opinião dos empresários. O destaque é a Secretaria de Finanças da Prefeitura Municipal de Vitória da Conquista. Com uma média de 1,7, esta Secretaria encontra-se abaixo do nível de pouco eficiente, demonstrando ser um setor que apresenta maior morosidade e dificuldades nas atividades de abertura da empresa. Dentre os motivos apontados pelos entrevistados, a organização e a visita do fiscal na Secretaria de Finanças são as mais substanciais.

Logo, esses motivos, vistos como uma dificuldade para dar continuidade no processo de regularização da empresa remete principalmente à administração do setor, no qual a pessoa responsável segue padrões e normas que são ditados por leis e regulamentos excessivamente burocráticos. A principal dificuldade apontada na pesquisa quanto ao processo de abertura da empresa é, portanto, o excesso de burocracia. Citada como geradora de morosidade no processo e bloqueadora de 
eficiência dos servidores públicos, a burocracia também é vista por alguns como um importante mecanismo de controle.

A pesquisa aponta que os servidores são os menos responsabilizados. Certamente, há uma cultura de acomodação que alguns servidores seguem, diante de benefícios e estabilidade que possuem. Porém, suas ações são dificultadas pela rigidez burocrática e, assim, não conseguem exercer com mais eficiência suas atividades. $\mathrm{O}$ baixo desempenho de servidores públicos é considerado também como dificuldade que influencia, indiretamente, como desaceleradores do processo empreendedor, pois eles são responsáveis pela morosidade na abertura de empresas.

É possível observar que, em geral, as dificuldades possuem relação com o tempo de abertura, seja pelo excesso de exigências da burocracia ou pelo baixo desempenho dos servidores públicos, que acabam atrasando a abertura do negócio. O tempo excessivo na abertura de empresas desacelera o processo empreendedor de proporcionando um tempo ocioso sem gerar renda. Esse tempo em que a empresa está em processo de abertura, além de gerar despesas ao empresário, diminuindo seu capital para investimentos na empresa, também impede a contratação de trabalhadores, a arrecadação de tributos e, consequentemente, a circulação de mercadorias. Tais impedimentos desaceleram o desenvolvimento econômico e social do local e da região. Tal condição impacta negativamente no desenvolvimento e crescimento de Vitória da Conquista, enquanto cidade média, que influencia tantas outras, afinal é incontestável a importância da indústria para promoção do desenvolvimento de uma região de influência. Conforme pesquisa realizada pelo CNI - Confederação Nacional da Indústria (2014), a população brasileira acredita que a indústria tem um papel importante no desenvolvimento do país.

Para a população brasileira, a indústria tem papel de destaque no desenvolvimento econômico e social do Brasil. Há praticamente um consenso entre os brasileiros que ter uma indústria forte é prioridade e que o Brasil precisa investir mais em sua indústria. A indústria aparece em primeiro lugar quando são ordenados os setores mais importantes para o crescimento do país e há uma clara preferência para que novos empreendimentos sejam do setor industrial. (CNIIBOPE, 2014. p. 9).

Dados dessa mesma pesquisa apontam que $33 \%$ consideram a indústria o setor mais importante para o país, seguindo da agropecuária com $17 \%$. Ainda segundo a pesquisa, $96 \%$ acham que a indústria é importante ou muito importante para o 
crescimento da economia e $95 \%$ acreditam que a indústria é importante ou muito importante para a criação de empregos. Portanto, apesar da desaceleração da indústria no país, conforme dados da FIESP, a população acredita e vê uma grande importância do papel da indústria, enquanto fomentadora de uma melhor qualidade de vida da população. E, obviamente, que o fator tempo é determinante na agilidade dos segmentos industriais que, ora se propõem a atuar no mercado.

Diante do exposto percebe-se a urgência de melhorias, especialmente em relação Secretaria de Finanças da Prefeitura Municipal de Vitória da Conquista, adotando um gerenciamento mais eficaz de seus processos e visita de fiscais, com intuito de proporcionar maior agilidade na liberação das licenças. É fundamental ainda que haja articulação entre empresários, contadores, políticos e responsáveis pelos setores, a fim de debater tais dificuldades encontradas para que ações sejam desenvolvidas em prol da otimização desses processos.

\section{Referências}

ALVES, Rita de Cássia Oliveira Lima. A influência de uma cidade media do sudoeste da Bahia: O caso de Vitória da Conquista. Tese: Doutorado. Universidade de Barcelona -Barcelona, 2014

BRASIL. Instituto Brasileiro de Geografia e Estatísticas. IBGE. Brasil em síntese. Brasília: IBGE 2014. Disponível em: http://brasilemsintese.ibge.gov.br/servicos/numero-de-empresas-por-segmento-deservico.html. Acesso em: Agosto/2017

Lei Complementar no 123, de 14 de dezembro de 2006. Institui o Estatuto Nacional da Microempresa e da Empresa de Pequeno Porte. Disponível em: <http://www.planalto.gov.br/ccivil_03/leis/LCP/Lcp123.htm\#art89> Acesso em: 14 de abr, 2017.

Lei Complementar $\mathbf{n}^{\circ}$ 155, de 27 de outubro de 2016. Altera a Lei

Complementar $\mathrm{n}^{\mathrm{0}}$ 123, de 14 de dezembro de 2006. Disponível em:

<http://www.planalto.gov.br/ccivil_03/leis/LCP/Lcp155.htm >Acesso em: 14 de abr, 2017.

CNI-IBOPE. Retratos da sociedade brasileira: a indústria brasileira na visão da população. Maio 2014 / Confederação Nacional da Indústria. - Brasília: CNI, 2014.

IBPT. Instituto Brasileiro de Planejamento e Tributação. Empresômetro Inteligência de Mercado. 2017. Disponível em: https://listas.empresometro.com.br/. Acesso em: Abril/2017. 
Empresômetro MPE. 2017. Disponível em:

http://empresometro.cnc.org.br/estatisticas. Acesso em: Abril/2017.

FIGUEIREDO, A. K. S. Desenvolvimento, polarização e desigualdades: uma análise multidimensional do Território do Sudoeste Baiano. 2016. 125 f. Dissertação (Mestrado em Economia Regional e Políticas Públicas). Universidade Estadual de Santa Cruz, Ilhéus, 2016.

PERROUX, F. A Economia do século XX. Porto: Herder, 1967.

PMVC. Prefeitura de Vitória da Conquista. Redesim entra em vigor nessa terça-feira, $1^{\circ}$ de abril. Disponível em: < http://www.pmvc.ba.gov.br/redesim-entra-em-vigornessa-terca-feira-1o-de-abril/ > Acesso em: 30 de maio, 2017.

ROVEDA, Vinicius. Dificuldades mais comuns ao tentar registrar uma empresa. Blog Conta Azul. Disponível em: https://blog.contaazul.com/dificuldades-pararegistrar-empresa/ Acesso em: 13 de abr. 2017.

SEBRAE. Serviço Brasileiro de Apoio às Micro e Pequenas Empresas. Boletim Estudos e Pesquisas. Junho/2017. 2017. Disponível em: https://www.sebrae.com.br/

Sebrae/Portal\%20Sebrae/Anexos/estudos-e-pesquisas-junho-2017.pdf. Acesso em: Agosto/2017

Perfil dos pequenos negócios. DataSEBRAE. 2017a. Disponível em: http://datasebrae.com.br/perfil-dos-pequenos-negocios/\#quantos. Acesso em: Agosto/2017

Critérios de classificação de empresas: $M E I-M E$ - EPP. 2017b. Disponível em: http://www.sebrae-sc.com.br/leis/default.asp?vcdtexto=4154 Acesso em: 12 de abr. de 2017.

Participação das Micro e Pequenas Empresas na Economia Brasileira (2014). 2017c. Disponível em: <https://www.sebrae.com.br/Sebrae/Portal\%20Sebrae/ Estudos \%20e\%20Pesquisas/Participacao\%20das\%20micro\%20e\%20pequenas\%20empr esas.pdf> Acesso em: 30 de mar, 2017.

Passo a passo para o registro da sua empresa. Disponível em: $<$ https://www.sebrae.com.br/sites/PortalSebrae/artigos/passo-a-passo-para-o-registroda-sua-empresa,665cef598bb74510VgnVCM1000004c00210aRCRD> Acesso em: 01 de abr. 2017.

SOUZA, N. J. Desenvolvimento econômico. 5. ed. rev - São Paulo: Atlas, 2005

Recebido em: 22/10/2017

Aceito para publicação em: 30/11/2017 